\title{
Effects of green algal mats on bivalves in a New England mud flat
}

\author{
M. Thiel ${ }^{*}$, L. M. Stearns \& L. Watling \\ Darling Marine Center, University of Maine; Walpole, ME 04573, USA
}

\begin{abstract}
Concurrent with the spread of green algal mats on tidal flats, reports of macrofauna dieoffs under dense algal mats have increased in numbers. Bivalves seem to be particularly affected by persistent dense algal mats. Bivalve species with a long extendible siphon seem to be less affected underneath algal mats, but no distinction has been made in the past between species with short and those with long siphons. We examined effects of green algal mats on two bivalve species with relatively long siphons, Mya arenaria and Macoma balthica, on an intertidal mudflat in New England. Abundances of $M$. arenaria declined substantially during the study period when a thick green algal mat covered the mudflat for several months. Numbers of the small bivalve Gemma gemma also decreased substantially, whereas abundances of $M$. balthica showed minimal variation during the time of algal coverage. In algae removal/addition experiments numbers of $M$. arenaria decreased. but effects were only significant in an algal addition to previously algal-free mudflat areas. Abundance of $M$. balthica did not change significantly in the algal removal/addition experiments. Over the time period of the experiment ( 9 weeks), $M$. arenaria showed measurable size increase in uncovered mudflat areas, but not underneath algal mats. Similarly, M. balthica only increased in size in the uncovered mudflat area. From these results it is concluded that $M$. balthica can survive time periods of dense algal coverage because it is able to penetrate through the algal mat with its long extendible siphon, and thus can reach well-oxygenated water layers above the mat. M. arenaria with its thick, less extendible, siphon cannot push through dense algal mats and therefore is more likely to die underneath persistent algal mats.
\end{abstract}

\section{INTRODUCTION}

Green algae, where forming a dense mat over intertidal mud flats or shallow soft-bottoms, are detrimental to some underlying soft-bottom infauna (Perkins \& Abbott, 1972; Nicholls et al., 1981; Soulsby et al., 1982; Raffaelli et al., 1991; Bonsdorff, 1992). Bivalves in particular are affected, and often die off in large numbers under mats which persist for extended time periods. Reports of bivalve die-offs repeatedly mention short-siphoned species such as Cerastoderma spp., Abra spp. and Tapes decussatus (Perkins \& Abbott, 1972; Nicholls et al., 1981; Breber, 1985). Long-siphoned species such as Mya arenaria. Macoma sp. and Scrobicularia plana rarely emerge in these reports, although they comprise abundant infauna in areas where mass growth of green algae frequently occurs. We were particularly interested in the fate of the soft-shell clam Mya arenaria, which is a commercially important species along the coasts of New England. Mass growth of green algae has been observed on tidal flats in this area (Vadas \& Beal, 1987; own obs.). Nega-

- Present address: Smithsonian Marine Station, 5612 Old Dixie Highway, Fort Pierce, Fla 34946, USA 
tive effects of green algal mats on economically important bivalves have been suspected, but to our knowledge no studies have been conducted to examine this suspicion. Despite the substantial spread of dense green algal mats on tidal flats in many coastal areas of the world, surprisingly little is known about direct and indirect effects of these algal beds on commercially important species.

In this study we monitored the seasonal abundance of Mya arenaria, Gemma gemma and Macoma balthica along a tidal transect of a New England mud flat. In order to examine the effect of green algal mats on the two bivalve species with long siphons ( $M$. arenaria and $M$. balthica), we conducted experiments in which we removed or added algae on the intertidal mudflats. $M$. arenaria has a relatively thick and sturdy siphon, whereas $M$. balthica has a thin and very mobile siphon. G. gemma has a short siphon and lives close to the sediment surface. All three species co-occur on tidal flats in New England, but only $M$. arenaria is of commercial interest. Stocks of $M$. arenaria can fluctuate substantially and the reasons for these fluctuations often remain undiscovered (Wallace, 1997). In our study we examined the impact of green algal mats on $M$. arenaria and the co-occurring $M$. balthica.

\section{MATERIALS AND METHODS}

\section{Study area}

The study was conducted in Lowes Cove, an intertidal mudflat where only during the last few years dense green algal mats have been observed (own observations). Mya arenaria, Macoma balthica and Gemma gemma are abundant in Lowes Cove, and clam-diggers frequently exploit the soft-shell clam resources on this mudflat. Lowes Cove is a sheltered cove on the Damariscotta River Estuary, Maine, USA, where salinities are about 32 , and water temperatures vary over the course of the year between $-1^{\circ} \mathrm{C}$ and $19^{\circ} \mathrm{C}$. The sediment in the cove is silty to silty clay; the organic matter content of the sediments varies between $2.5 \%$ in the intertidal and $3.5 \%$ in the shallow subtidal (Thiel, 1997). Green algae cover large parts of the mudflats during the late summer through fall, when up to $375 \mathrm{~g}$ dry weight $\mathrm{m}^{-2}$ have been measured (Thiel \& Watling, in press). The green alga Enteromorpha prolifera is the major component within the dense algal mats in Lowes Cove.

\section{Survey}

Sediment samples were taken with cores of $176 \mathrm{~cm}^{2}$ surface area to a depth of $15 \mathrm{~cm}$, and sieved with a 500- $\mu \mathrm{m}$ mesh. Six replicate samples were taken at each of 5 stations along a tidal transect from the upper intertidal to the shallow subtidal (Fig. 1). All 5 stations were sampled in May, August and November 1994 and in February/March 1995.

\section{Experiments}

Two experiments were conducted over a 9-week period between 2 September and 4 November 1995 when large areas of the mudflat were covered by green algae. In one experiment (= large-scale experiment) we removed algae from an area with thick algal mats, in a second experiment we established small algal mat plots in a nearby area which 


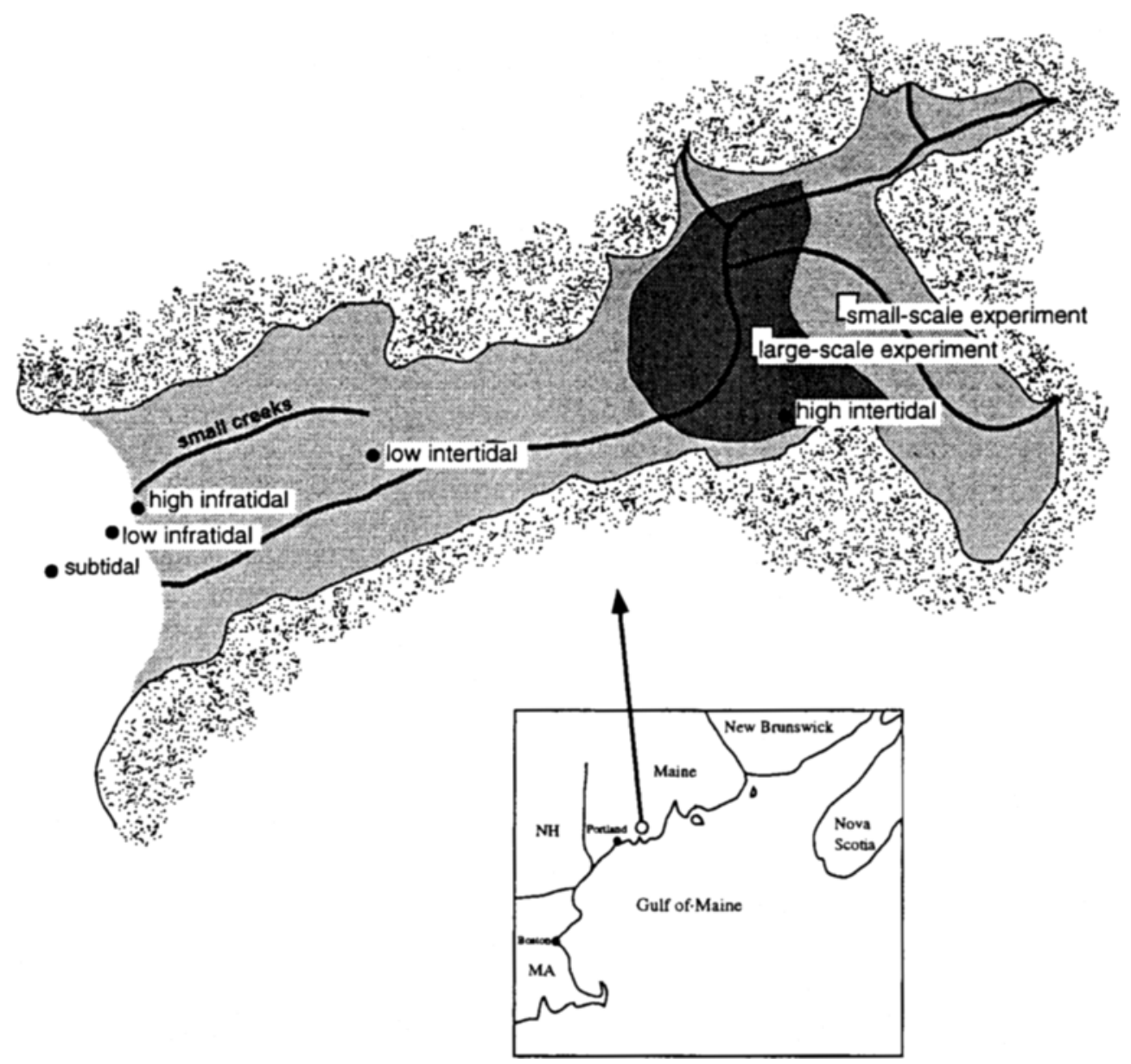

Fig. 1. Study area in Lowes Cove, Maine, with the five sampling stations along tidal transect, and the sites of the two experiments conducted in autumn 1995; light shading - tidal flats, dark shading - areas commonly covered by green algal mats

had not previously been covered by green algae (small-scale experiment - Fig. 1). Within each area, 6 replicate samples $\left(176 \mathrm{~cm}^{2}\right.$ surface area) were taken to a depth of $15 \mathrm{~cm}$ and sieved over a 2 -mm mesh. This mesh-size was selected as the 1995-recruits were almost completely absent from the experimental sites. All clams retained on the 2-mm mesh were counted and their size measured.

\section{Large-scale experiment}

We carefully cleared an area of $25 \mathrm{~m}^{2}$ of its thick green algal layer (in the following termed 'cleared'). The removed algae were placed in an immediately adjacent $25 \mathrm{~m}^{2}$ area ('double-cover'), where most of them stayed during the experimental period. Surrounding areas with undisturbed algal mats served as controls, 6 replicate samples 
were taken in each of the three plot areas (the 'cleared', the 'double-cover' and the 'control'). Sampling of the three areas was done at the beginning and end of the experiment. For each plot, the Mann-Whitney U-test was used to test for differences in bivalve abundance between the beginning and the end of the experiment. Student's t-test was used to test for differences in size between the beginning and the end of the experiment.

\section{Small-scale experiment}

We collected green algae and covered 6 small experimental plots (each plot $1 \mathrm{~m}^{2}$ ) with an artificial dense algal mat ('algal plots') in an area not covered by algal mats during the 1995 season. The algae in these plots were kept in place by about 20 small wooden anchors (about $1 \mathrm{~cm}$ in diameter and $25 \mathrm{~cm}$ long). In a second set of 6 plots (each plot $1 \mathrm{~m}^{2}$ ) we placed only the wooden anchors as a control for potential effects of these anchors ('anchor-plot'). Undisturbed areas in immediate vicinity of the two sets of plots served as controls.

Six random replicates were taken from the control area at the beginning and end of the experiment, and one sample each was taken from each of the 6 'algal plots' and from each of the 6 'anchor plots' at the end of the experiment. A one-way ANOVA was used to test for differences between the different treatments.

\section{RESULTS}

\section{Seasonal abundance of bivalves along tidal transect}

Mya arenaria reached numbers of up to 6000 individuals $\mathrm{m}^{-2}$ in the upper intertidal, but numbers in the lower intertidal and shallow subtidal were much lower (Fig. 2). In the upper intertidal there was a strong increase of $M$. arenaria abundance immediately after the yearly spatfall (Fig. 2). Most newly settled $M$. arenaria disappeared during the months following the spat fall. Macoma balthica showed the same spatial distribution pattern as $M$. arenaria with highest abundances in the upper intertidal (Fig. 3). There was little seasonal variation in $M$. balthica abundance in the upper intertidal (Fig. 3). The small bivalve Gemma gemma was very abundant in the upper intertidal (Fig. 4), but numbers decreased substantially during the time period of dense algal coverage at this station (Fig. 4).

\section{Effects of algal removal/addition on Mya arenaria and Macoma balthica}

\section{Large-scale experiment}

Both Mya arenaria and Macoma balthica decreased in numbers over the time period of the experiment in all three areas (control, cleared, double-cover), but the changes were not significant (Mann-Whitney U-test, p > 0.05) (Fig. 5). In the cleared area, M. arenaria significantly increased in size (t-test, $p<0.01$ ), whereas no size change was recognizable in the other two areas (control-cover, double-cover) over the 2-month period (t-test, $p>0.05$; Fig. 6). No significant size changes were observed for $M$. balthica (t-test, $p>0.05$; Fig. 6). 


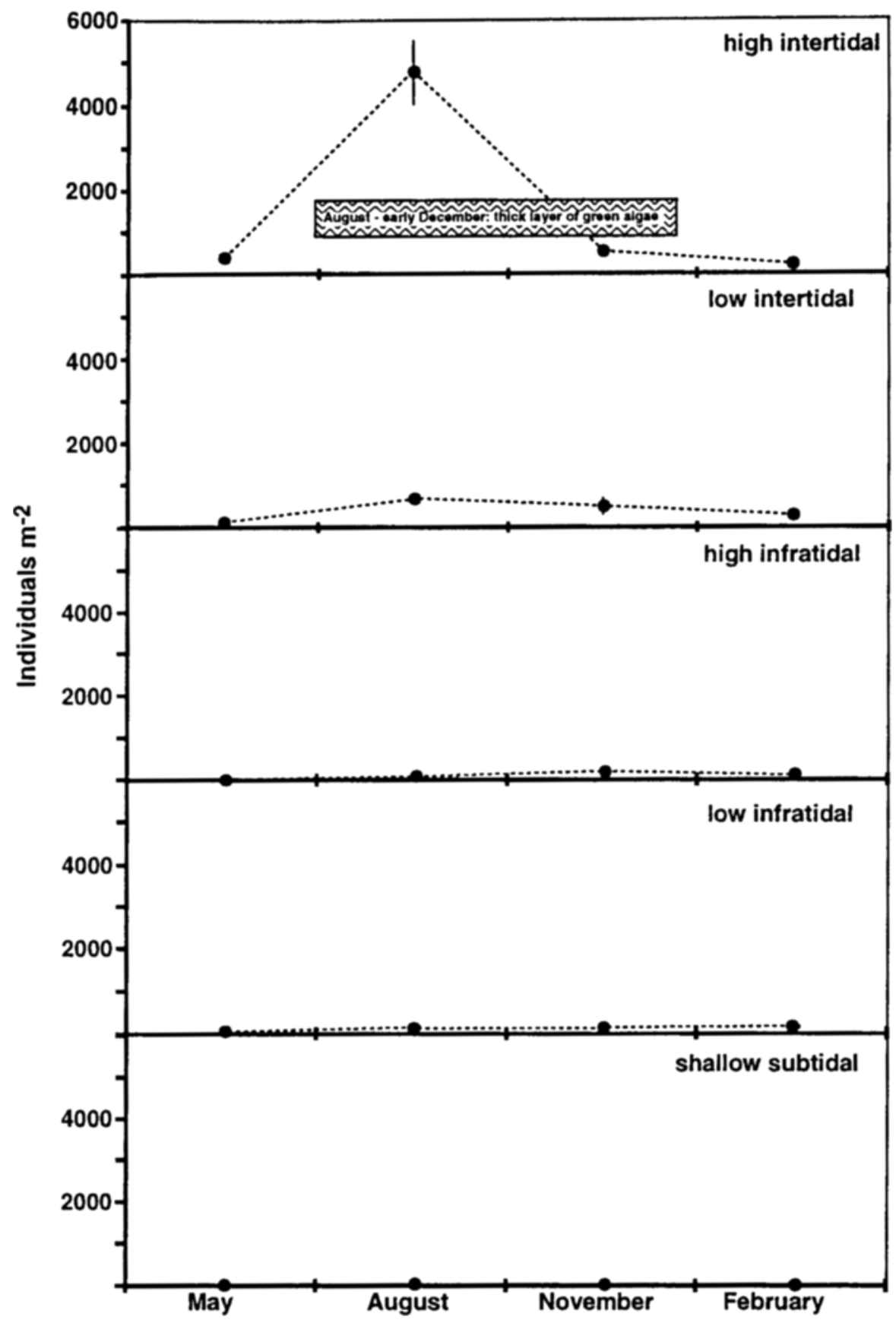

Fig. 2. Numbers of Mya arenaria (ind. $\mathrm{m}^{-2} \pm 1$ std err.) at the five different stations of the tidal transect in Lowes Cove; at each sampling date six replicates $\left(176 \mathrm{~cm}^{2}\right.$ surface area, $15 \mathrm{~cm}$ deep) were

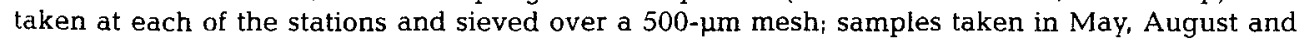
November 1994 and February/March 1995 


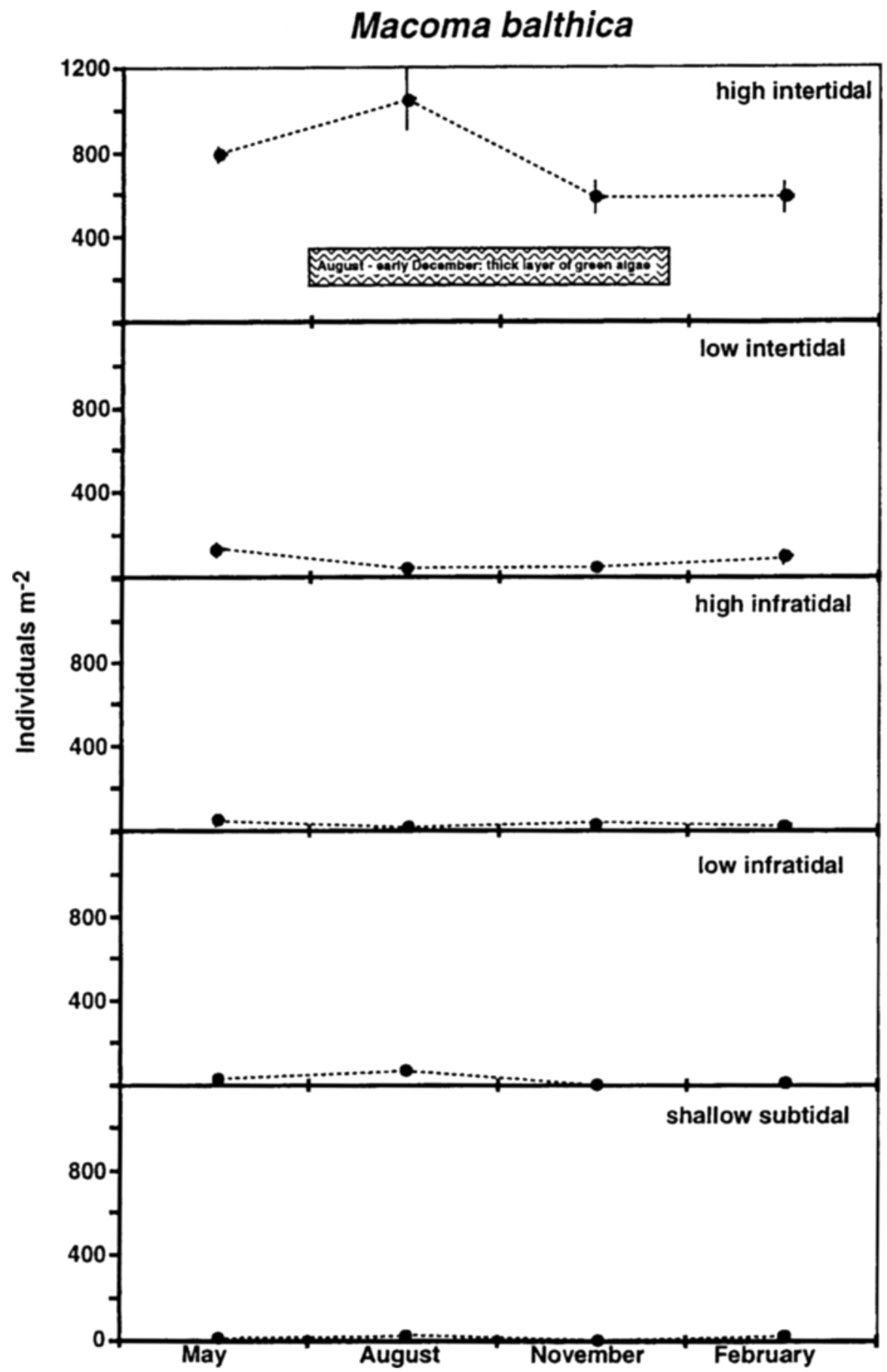

Fig. 3. Numbers of Macoma balthica (ind. $\mathrm{m}^{-2} \pm 1$ std err.) at the five different stations of the tidal transect in Lowes Cove; see also legend to Fig. 2 
Gemma gemma

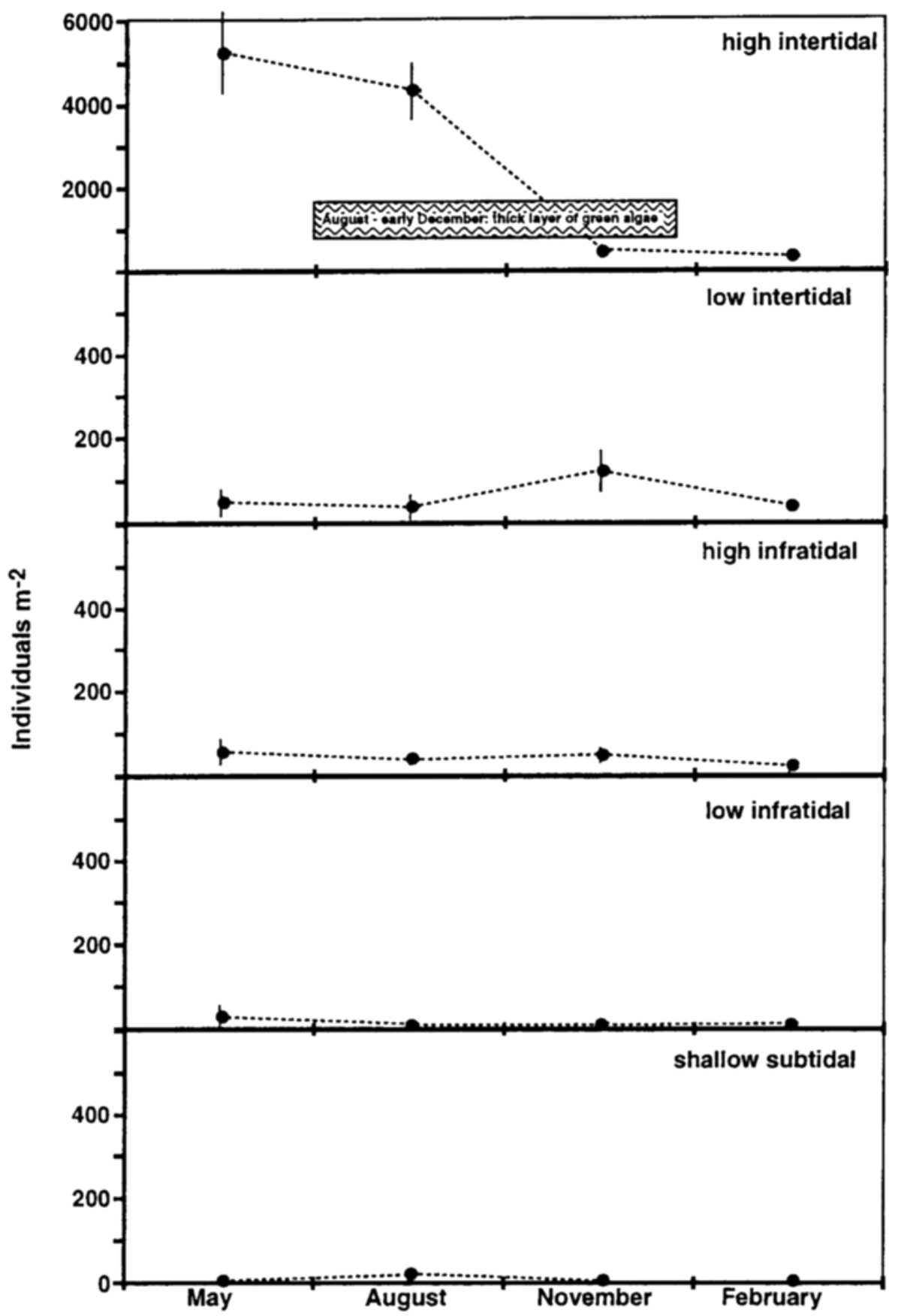

Fig. 4. Numbers of Gemma gemma (ind. $\mathrm{m}^{-2} \pm 1 \mathrm{std}$ err.) at the five different stations of the tidal transect in Lowes Cove; see also legend to Fig. 2 


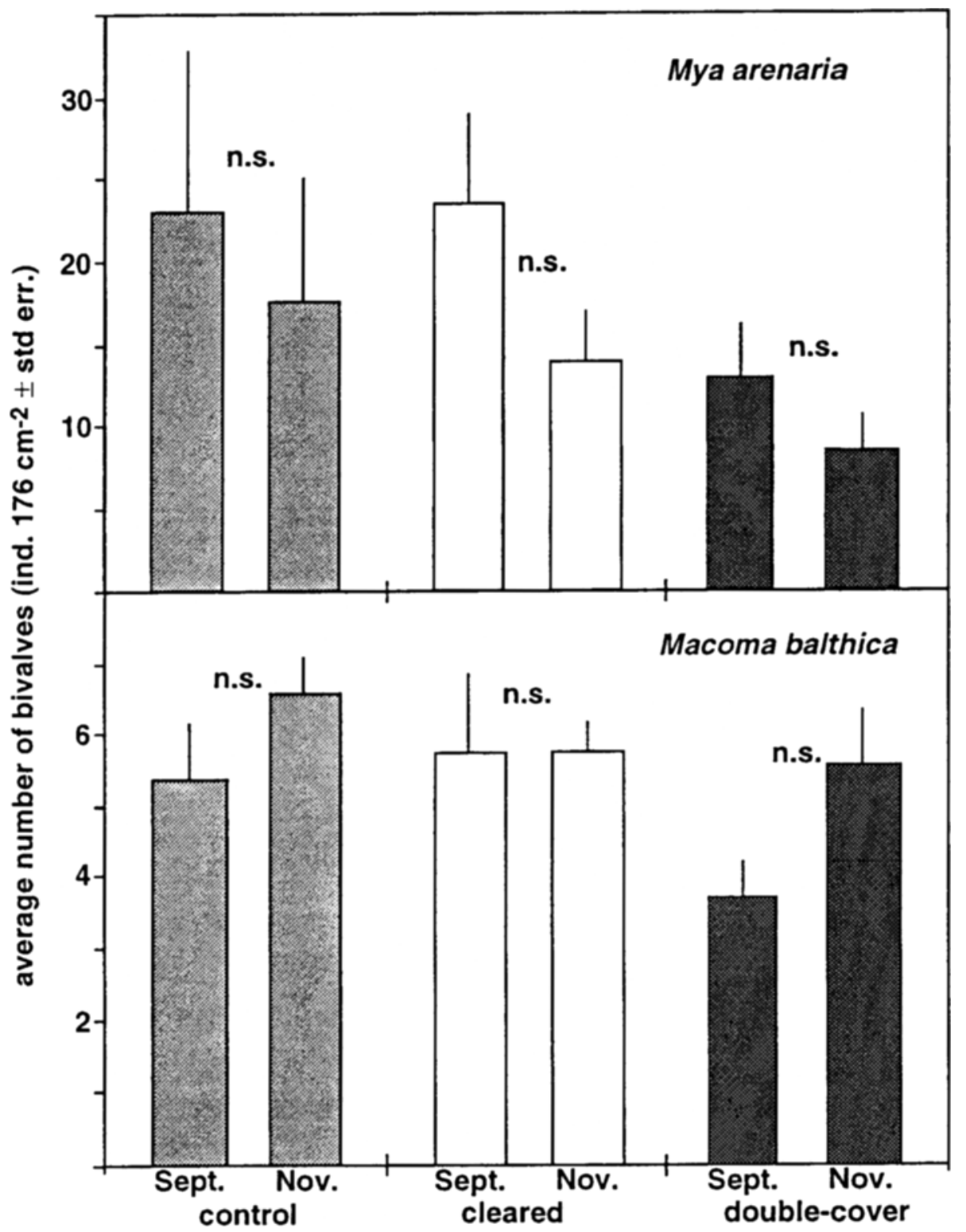

Fig. 5. Average numbers (ind, $176 \mathrm{~cm}^{-2} \pm 1$ std err.) of (a) Mya arenaria and (b) Macoma balthica in the three different areas (cleared, double-cover and control) of the large-scale experiment; 6 replicates (176 $\mathrm{cm}^{2}$ surface area, $15 \mathrm{~cm}$ deep) were taken in each area at the beginning and end of the experiment and sieved over a $2-\mathrm{mm}_{\text {mesh; }}$ for each plot, the Mann-Whitney U-test was used to test for differences in bivalve abundance between the beginning and the end of the experiment; n.s. $p>0.05$ 


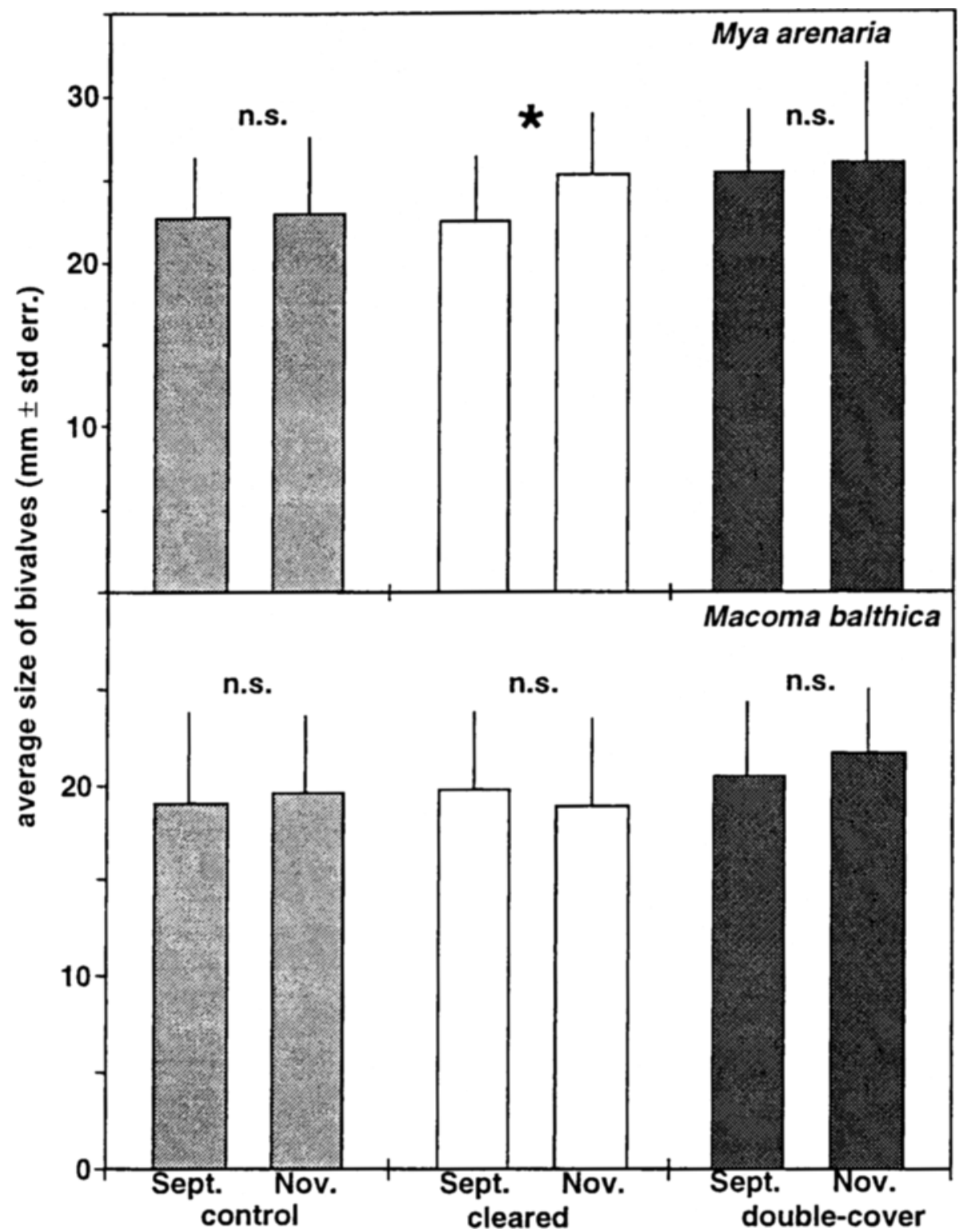

Fig. 6. Average sizes of Mya arenaria and Macoma balthica (in $\mathrm{mm} \pm 1$ std err.) in the three different areas (cleared, double-cover and control) of the large-scale experiment; all clams from the 6 replicates for each respective area and each respective sampling date were pooled; all clams retained on a 2-mm mesh included in analysis; Student's t-test was used to test for differences in size between the beginning and the end of the experiment; n.s. p $>0.05,^{*} p<0.05$ 


\section{Small-scale experiment}

Numbers of Mya arenaria in the algal plots in November were significantly different from the numbers in control plots in September (one-way ANOVA, $p<0.05$ ), but not from those in the anchor plots and the control area in November (Fig. 7a). No significant change was observed in the abundance of Macoma balthica (Fig. $7 \mathrm{~b}$ ). M. arenaria were significantly larger in both experimental plot types and in the control plots in November than in the control plots in September (Fig. 8). In November, $M$. arenaria in the algal-free control areas were also significantly larger than those in the anchor and algal plots. Only the $M$. balthica from the control plots in November were significantly different from the control plots in September (Fig. 8).

\section{DISCUSSION}

Bivalves Mya arenaria, Macoma balthica and Gemma gemma decreased in abundance during the time periods of algal mat coverage in the mid intertidal. The decline in abundance was much more substantial for $M$. arenaria and $G$. gemma than for $M$. balthica. In algal removal/addition experiments no effects on $M$. balthica abundances were observed, whereas numbers of $M$. arenaria significantly decreased under a thick experimental algal mat in one of two experiments.

The mass growth of dense algal beds in many coastal areas of the world during the last decades have been related to increased levels of eutrophication (e.g. Perkins \& Abbott, 1972; Buttermore, 1977; Nicholls et al., 1981; Soulsby et al., 1982; Reise, 1983, 1984; Reise et al., 1989; Raffaelli et al., 1989, 1991; Bonsdorff, 1992; Isaksson et al., 1994; Peterson et al., 1994; Reise \& Siebert, 1994). Strict measures regarding sewage effluents have improved the situation in some areas (Hardy et al., 1993).

Algal mats have a significant impact on the community composition within the underlying soft-bottoms (Thrush, 1986; Everett, 1994; Norkko \& Bonsdorff, 1996a, b). The dense algal mats can cause immediate death in underlying infauna due to reduced oxygen-supply and increased concentrations of toxic substances such as $\mathrm{H}_{2} \mathrm{~S}$ and $\mathrm{NH}_{4}{ }^{+}$(Perkins \& Abbott, 1972; Nicholls et al., 1981; Soulsby et al., 1982; Raffaelli et al., 1989, 1991; Bonsdorff, 1992), they may prevent recruits from entering the sea bed (Ólafsson, 1988; Bonsdorff, 1992) or they may indirectly affect the soft-bottom infauna by providing shelter to epibenthic predators (Isaksson et al., 1994). Where algal mats persist over long time periods, they start decaying on the lower side and the underlying sediments can become completely anoxic. Due to restricted exchange with the overlying well-oxygenated water column, the waters trapped under the decaying algal mats may reach hypoxic levels (Norkko \& Bonsdorff, 1996a, b). Large numbers of the original soft-bottom infauna including bivalves may die off when covered by persistent algal mats. Among the bivalves, species with short siphons are most severely affected by anoxic situations under the algal mats (Perkins \& Abbott, 1972; Nicholls et al., 1981; Breber, 1985; Metzmacher \& Reise, 1994). In our study we did not observe any obvious detrimental effects of the algal mats on the bivalve $M$. balthica, despite the fact that the algal mats persisted for time periods of several weeks. Similarly. Hull (1987) found that $M$. balthica abundances did not significantly decrease under experimental algal plots, but Perkins \& Abbott (1972). Bonsdorff (1992) and Norkko \& Bonsdorff (1996b) mentioned negative effects of algal mats on $M$. balthica, particularly juvenile individuals. Under algal mats, we often observed me- 


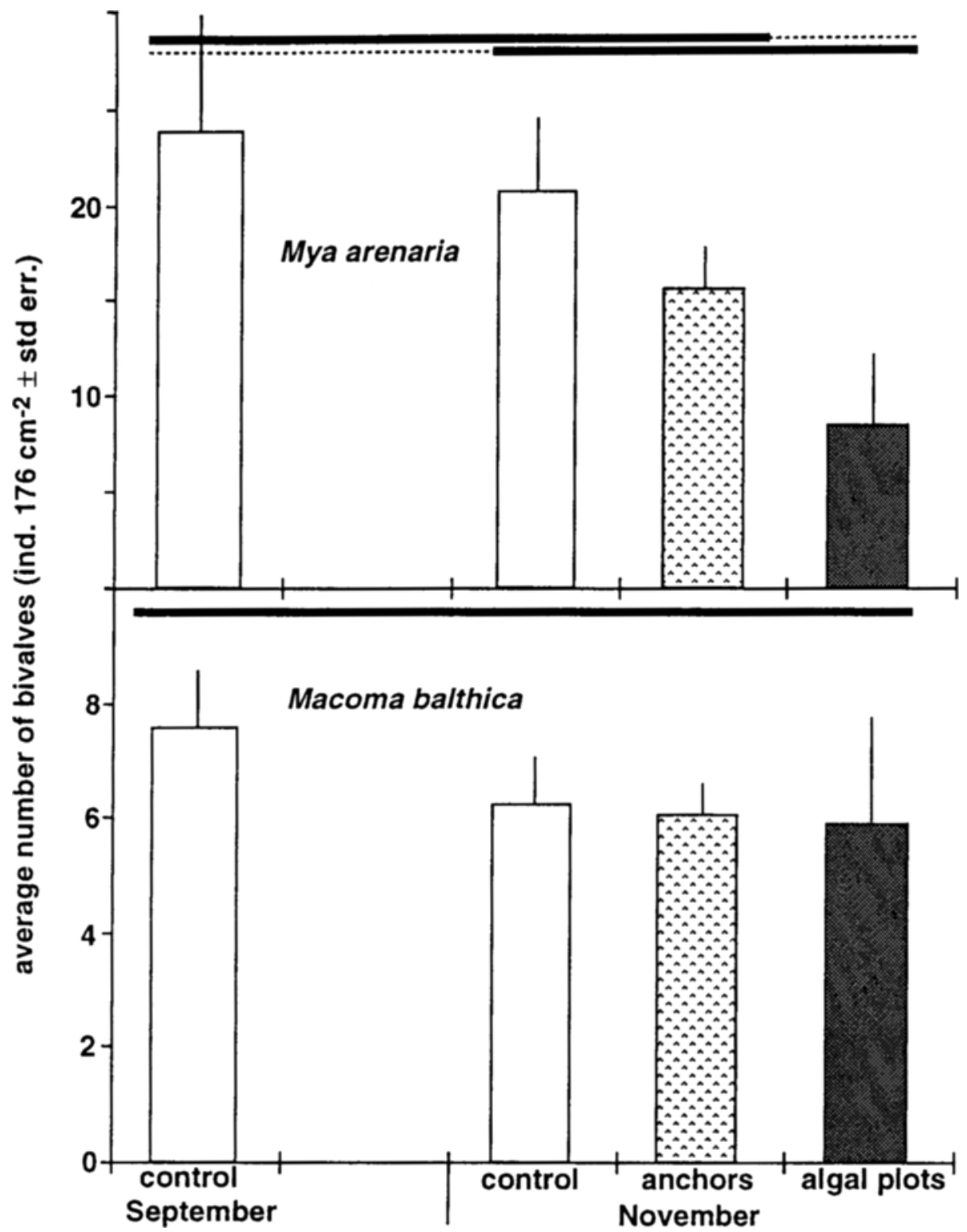

Fig. 7. Average numbers (ind. $176 \mathrm{~cm}^{-2} \pm 1$ std err.) of (a) Mya arenaria and (b) Macoma balthica in the two types of small-scale experimental plots (algal plots and anchor plots) and in the control plots; 6 control replicates were taken at the beginning and 6 at the end of the experiment, and at the end of the experiment one sample was taken in each of 6 replicate algal plots (each plot $1 \mathrm{~m}^{2}$ ) and each of 6 replicate anchor plots (each plot $\left.1 \mathrm{~m}^{2}\right)$; samples $\left(176 \mathrm{~cm}^{2}\right.$ surface area, $15 \mathrm{~cm}$ deep) were sieved over a 2-mm mesh; black lines indicate that no significant differences were found - one-way ANOVA, $p>0.05$ 


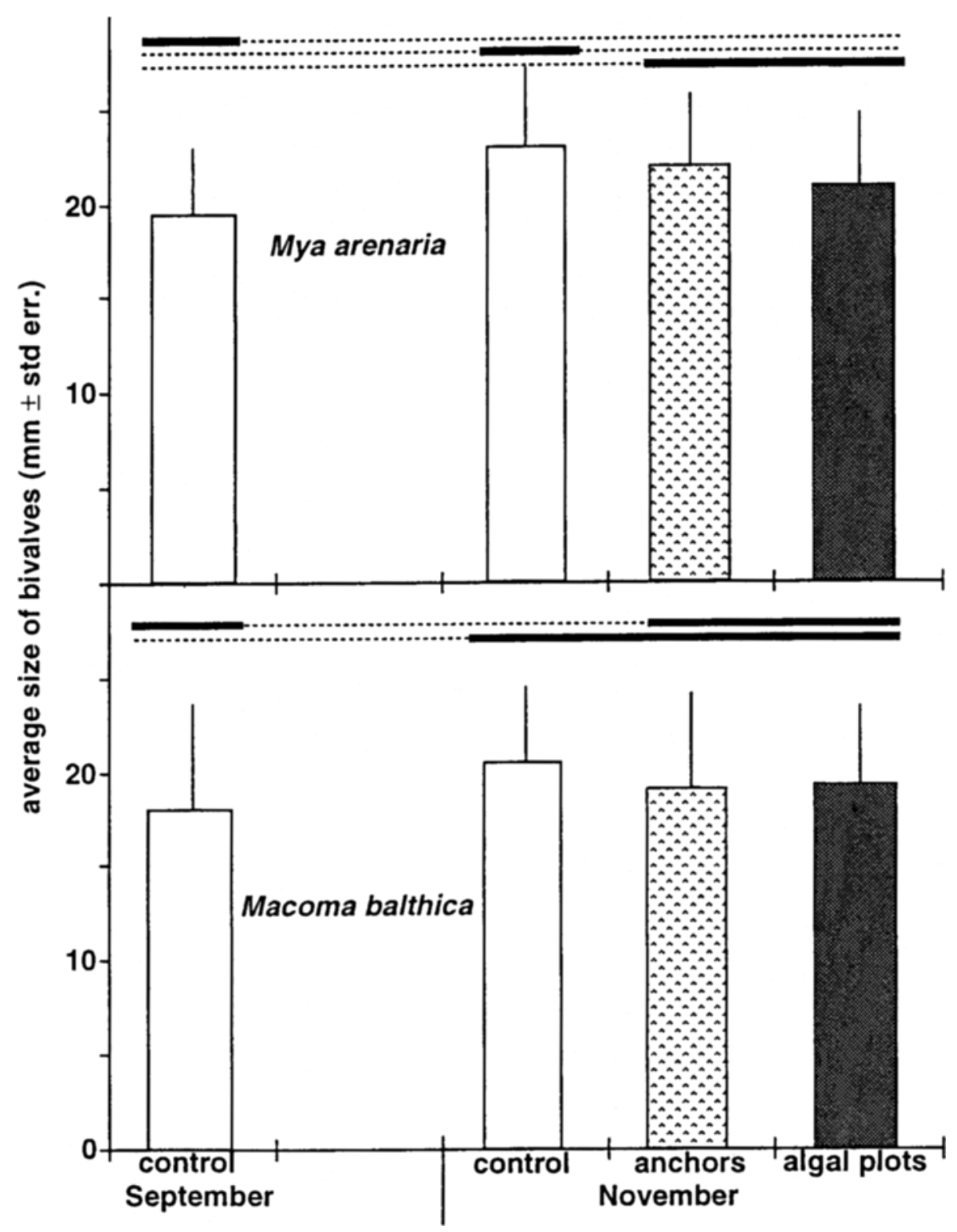

Fig. 8. Average sizes of Mya arenaria and Macoma balthica (in $\mathrm{mm} \pm 1$ std err.) in algal plots, anchor plots, and in control plots of the small-scale experiment; 6 control replicates were taken at the beginning and 6 at the end of the experiment, and at the end of the experiment one sample was taken in each of 6 replicate algal plots (each plot $1 \mathrm{~m}^{2}$ ) and each of 6 replicate anchor plots (each plot $1 \mathrm{~m}^{2}$ ): clams of the 6 replicates for each respective area and each respective sampling date were pooled; all clams retained on a $2-\mathrm{mm}$ mesh included in analysis; black lines connected by dotted lines indicate that no significant differences were found - one-way ANOVA, $p>0.05$ 
dium-sized and apparently weakened $M$. arenaria lying on the sediment surface, but never $M$. balthica. In the small-scale experiment in which we anchored a thick algal mat at the sediment surface, many bivalves $M$. arenaria died during the experiment, but almost no $M$. balthica. With its relatively narrow, extendible siphon, $M$. balthica can penetrate through moderately thick algal mats and thus reach into well oxygenated water layers. With its muscular foot $M$. balthica may well be able to move upwards in the sediment in response to an overlying algal mat (Norkko, 1998). In contrast, $M$. arenaria with its relatively thick siphon and reduced mobility especially in older individuals, might not be able to push through the algal mats. Similarly, Gemma gemma, which possesses a very short siphon (hardly extending beyond the shell), disappeared almost completely during the time of dense algal coverage in 1994. Size data from our experiments provide indication that $M$, arenaria in algal-free areas significantly increased in size during the 9 weeks of the experiments, whereas $M$. arenaria under algal coverage did not grow substantially in the large-scale experiment. The apparent significant size increase in algal plots in the small-scale experiment is probably an artifact due to a significant die-off largely of medium-sized or small individuals (compare Figs 7 \& 8) similar to what Norkko \& Bonsdorff (1996b) discussed for M. balthica under artificial algal mats in the Baltic Sea. The apparent growth stagnancy of both $M$. arenaria and $M$. balthica under the algal mats is probably due to diminished food-supply caused by reduced water exchange under the algae. In our study we did not collect any data on the condition of the bivalves under the algal mats. Future studies urgently need to address this issue: Long-lasting coverage by algal mats may not cause immediate death but may lead to sublethal conditions for bivalves due to persistent impoverished food-supply or exposure to toxic substances (e.g. $\mathrm{NH}_{4}{ }^{+}$; cf. Foolad, 1983, cited in Hull, 1987).

\section{CONCLUSIONS}

The bivalves Mya arenaria and Macoma balthica suffer under dense algal mats. Persistent algal mats can cause immediate death in $M$. arenaria, but not necessarily in $M$. balthica. Experiments provide indication for inhibited growth and sublethal effects on both species under algal mats. Effects of green algal mats on intertidal mud flats on the growth potential of these and other bivalves need to be addressed in future studies.

\section{LITERATURE CITED}

Bonsdorff, E., 1992. Drifting algae and zoobenthos - effects on settling and community structure. Neth. J. Sea Res. 30, 57-62.

Breber, P., 1985. On growing of the carpet-shell clam (Tapes decussatus [L.]): Two years' experience in Venice lagoon. - Aquaculture 44, 51-56.

Buttermore, R. E., 1977. Eutrophication of an impounded estuarine lagoon. - Mar. Pollut. Bull. 8, 13-15.

Everett, R. A., 1994. Macroalgae in marine soft-sediment communities: effects on benthic faunal assemblages. - J. exp. mar. Biol. Ecol, 175, 253-274.

Hardy, F. G., Evans, S. M. \& Tremayne, M. A., 1993. Long-term changes in the marine macroalgae of three polluted estuaries in north-east England. - J. exp. mar. Biol. Ecol. 172, 81-92.

Hull, S. C., 1987. Macroalgal mats and species abundance: a field experiment. - Estuar. coast. Shelf Sci. 25, 519-532.

Isaksson, I., Pihl, L. \& Montfrans, J. van, 1994. Eutrophication-related changes in macrovegetation 
and foraging of young cod (Gadus morhua L.): a mesocosm experiment. - J. exp. mar. Biol. Ecol. 177, 203-217.

Metzmacher, K. \& Reise, K., 1994. Experimental effects of tidal flat epistructures on foraging birds in the Wadden Sea. - Ophelia (Suppl.) 6, 217-224.

Nicholls, D. J., Tubbs, C. R. \& Haynes, F. N., 1981. The effect of green algal mats on intertidal macrobenthic communities and their predators. - Kieler Meeresforsch. (Sonderh.) 5, 511-520.

Norkko. A., 1998. The impact of loose-lying algal mats and predation by the brown shrimp Crangon crangon (L.) on infaunal prey dispersal and survival. - J. exp. mar. Biol. Ecol. 221, 99-116.

Norkko, A. \& Bonsdorff, E., 1996a. Rapid zoobenthic community responses to accumulations of drifting algae. - Mar. Ecol. Prog. Ser. 131, 143-157

Norkko, A. \& Bonsdorff, E., 1996b. Population responses of coastal zoobenthos to stress induced by drifting algal mats. - Mar. Ecol. Prog. Ser. 140, 141-151.

Olafsson, E. B., 1988. Inhibition of larval settlement to a soft bottom benthic community by drifting algal mats: an experimental test. - Mar. Biol. 97, 571-574.

Perkins, E. J. \& Abbott, O. J., 1972. Nutrient enrichment and sand flat fauna. - Mar. Pollut. Bull. 3. $70-72$.

Peterson, C. H., Irlandi, E. A. \& Black, R., 1994. The crash in suspension-feeding bivalve populations (Katelysia spp.) in Princess Royal Harbour: an unexpected consequence of eutrophication. - J. exp. mar. Biol. Ecol. 176, 39-52.

Raffaelli, D., Hull, S. \& Milne, H., 1989. Long-term changes in nutrients, weed mats and shorebirds in an estuarine system. - Cah. Biol. mar. 30, 259-270.

Raffaelli, D., Lima, J., Hull, S. \& Pont, S., 1991. Interactions between the amphipods Corophium volutator and macroalgal mats on estuarine mudflats. - J. mar. biol. Ass. U.K. 71, 899-908.

Reise, K., 1983. Sewage, green algal mats anchored by lugworms, and the effects on Turbellaria and small Polychaeta. - Helgoländer Meeresunters. 36, 151-162.

Reise, K., 1984. Indirect effects of sewage on a sandy tidal flat in the Wadden Sea. - Publ. Ser. Neth. Inst. Sea Res. 10, 159-164.

Reise, K., Herre, E. \& Sturn, M., 1989. Historical changes in the benthos of the Wadden Sea around the island of Sylt in the North Sea. - Helgoländer. Meeresunters. 43, 417-433.

Reise, K. \& Siebert, I., 1994. Mass occurrence of green algae in the German Wadden Sea. - Dt. hydrogr. Z. (Suppl.) 1, 171-180.

Soulsby, P. G., Lowthion, D. \& Houston, M., 1982. Effects of macroalgal mats on the ecology of intertidal mudflats. - Mar. Pollut. Bull. 13, 162-166.

Thiel, M., 1997. Extended parental care in a high food environment - 'Babies don't go in the mud'. In: The responses of marine organisms to their environment. Ed. by L. E. Hawkins \& S. Hutchinson with A. C. Jensen, J. A. Williams \& M. Sheader. - University of Southampton, Southampton, $163-170$.

Thiel, M. \& Watling, L., 1998, Effects of green algal mats on infaunal colonization of a New England mud flat - long-lasting but highly localized effects. - Hydrobiologia (in press).

Thrush, S. F. 1986. The sublittoral macrobenthic community structure of an Irish sea-lough: effect of decomposing accumulations of seaweed. - J. exp. mar. Biol. Ecol. 96, 199-212.

Vadas, R. L. \& Beal, B., 1987. Green algal ropes: a novel estuarine phenomenon in the Gulf of Maine. - Estuaries 10, 171-176.

Wallace, D. E., 1997. The molluscan fisheries of Maine. - NOAA tech. Rep. NMFS 127,63-86. 